\title{
Effect of maternal smoking on cord blood estriol, placental lactogen, chorionic gonadotropin, FSH, LH, and cortisol
}

\author{
Anastasia A. Varvarigou, ${ }^{1, *}$, Spyros G. Liatsis, \\ Pavlos Vassilakos ${ }^{2}$, George Decavalas ${ }^{3}$ and \\ Nicholas G. Beratis ${ }^{1}$ \\ 1 Department of Pediatrics, University of Patras, \\ Medical School, Rio, Patras, Greece \\ 2 Department of Nuclear Medicine Laboratory, \\ University of Patras, Medical School, Rio, Patras, \\ Greece \\ ${ }^{3}$ Department of Obstetrics and Gynecology, University \\ of Patras, Medical School, Rio, Patras, Greece
}

\begin{abstract}
Aim: To determine the effect of maternal cigarette smoking on cord blood concentrations of E3, hPL, $\beta-h C G$, $\mathrm{FSH}$, LH, and cortisol.

Methods: Hormone concentrations were measured in term neonates of 100 smoking and 100 non-smoking mothers.

Results: The median E3, hPL, $\beta$-hCG, FSH, LH and cortisol cord blood concentrations in the non-smoking mothers' offspring were $212 \mathrm{ng} / \mathrm{mL}, 2.00 \mu \mathrm{g} / \mathrm{mL}$, $57.5 \mathrm{mlU} / \mathrm{mL}, 0.10 \mathrm{mlU} / \mathrm{mL}, 0.20 \mathrm{mlU} / \mathrm{mL}$, and 14.3 $\mu \mathrm{g} / \mathrm{mL}$, respectively; in the smoking they were $163,1.39$, $45.4,0.10,0.20$, and 25.1 , respectively $(P=0.008,0.004$, $0.037,0.498,0.286,0.004$, respectively). There was a significant but poor negative correlation between number of cigarettes/day and E3 $(r=-0.163, P=0.021), h P L$ $(r=-0.191, P=0.007)$, and $\beta-h C G(r=-0.143, P=0.044)$, whereas the correlation with cortisol was positive $(r=0.259, P<0.0001)$. Multiple linear regression analyses showed that maternal smoking is a determinant of cord blood E3, hPL, $\beta$-hCG, FSH, and cortisol concentrations. Conclusions: Tobacco smoking is associated with a reduction in cord blood E3, hPL, and $\beta$-hCG concentrations, whereas it is associated with increased cortisol concentrations. The disturbed endocrine equilibrium of the fetus induced by tobacco smoking could have
\end{abstract}

\footnotetext{
${ }^{*}$ Corresponding author:

Dr. Anastasia A. Varvarigou, MD

Department of Pediatrics

University of Patras

Medical School

26504 Rio

Patras

Greece

Tel.: + 30-2610-999253

Fax: +30-2610-993543

E-mail: nata-var@med.upatras.gr
}

adverse consequences on the fetus and child since fetal brain is a target organ for hormonal actions.

Keywords: Chorionic gonadotropin; cord blood; cortisol; estriol; FSH; LH; maternal smoking; peptide hormones; placental lactogen; steroid hormones.

\section{Introduction}

Maternal smoking is an important factor for feto-infant morbidity and mortality [30]. Disruption of the endocrine equilibrium of the fetus is an adverse effect of prenatal smoking. Newborns exposed in utero to component(s) of tobacco smoke have increased cord blood concentrations of the stress-hormones prolactin, growth hormone [5] and cortisol [34]. Also, increased epinephrine and norepinephrine concentrations have been measured in the amniotic fluid of fetuses whose mothers smoked [10]. Thus, the increased blood pressure found in neonates and infants of smoking mothers [4] may have an endocrine origin, such as increased fetal concentrations of cortisol and catecholamines. Alternatively, increased blood pressure might be related to intrauterine growth restriction (IUGR) irrespective of the endocrine disturbance.

The corpus luteum is the principal source of estrogens during the first trimester, but subsequently estrogens are primarily synthesized by the placenta [33]. Placental estriol (E3) is first detectable in maternal serum at nine weeks of gestation [33], but because its concentrations increase more than 500-fold during pregnancy, and the exposure of the uterus and the fetus to the direct effect of newly synthesized E3 is immense, this hormone is a dominant estrogen in pregnancy [29, 33]. Fetal luteinizing hormone ( $\mathrm{LH}$ ) and follicle stimulating hormone (FSH) are produced by the anterior pituitary of the fetus and the patterns of fetal plasma concentration follow a parallel course [20]; they increase up to mid-gestation and thereafter decline, possibly because the fetal hypothalamus becomes progressively more sensitive to sex steroids synthesized by the placenta. The human chorionic gonadotropin (hCG) is secreted by the placental syncytiocytotrophoblast into both fetal and maternal circulation affecting the mother, placenta and fetus. Human placental lactogen (hPL) is also secreted by the syncytiocytotrophoblast primarily into the maternal circulation causing increased transport of glucose, fatty acids and amino acids to the fetus [14]. 
Although there are several reports indicating that the concentrations of hCG $[3,9,28,31], \mathrm{hPL}[6,23]$ and $\mathrm{E} 3$ $[3,23,28]$ are significantly (hCG, hPL) or slightly (E3) reduced in blood of pregnant women who smoke, the concentrations in cord blood of newborns whose mothers smoked during pregnancy remain largely unknown.

The histologic and physiologic alterations that take place at the interface between fetoplacental unit and mother regulate the secretion of steroid hormones, produced by hormonal signals originating from the fetoplacental unit into the maternal and fetal compartment [24]. Because of the endocrine compartmentalization of the maternal and the fetal circulation, hormone measurements in fetal blood are indicated to identify any disturbances in the endocrine equilibrium of fetuses whose mothers smoked during pregnancy. The aims of this study are to compare the concentrations of six hormones, E3, $\beta$-hCG, hPL, FSH, LH and cortisol, in cord blood of neonates born to smoking mothers with those of non-smoking mothers, and test the correlations between number of cigarettes smoked per day and hormone concentrations as well as between hormone concentrations and anthropometric parameters in the offspring of both smoking and non-smoking mothers, and finally to assess any independent determinants of cord blood hormones.

\section{Methods}

We studied 200 (100 male) newborns; 100 (50 male) were born to mothers who smoked during pregnancy (study group) and 100 (50 male) to mothers who did not smoke (control group). The study singleton neonates were successively enrolled provided that they were born at term, had clear amniotic fluid, an Apgar score $\geq 7$ at one and $5 \mathrm{~min}$, had no evident congenital anomalies and the parents agreed to participate. The control neonates were obtained randomly, following the delivery of a study neonate, provided that they fulfilled the entry criteria of the study. Neonates were delivered at the University Hospital of Patras from December 2006 to February 2008.

At the time of recruitment, mothers were subjected to an interviewer-administered questionnaire indicating their smoking status, and if they were smokers, the daily number of cigarettes smoked. As "number of cigarettes per day" we recorded that number of the third trimester. Subjects whose mothers discontinued smoking during pregnancy or admitted the use of any illicit substances were excluded from the study. Smokers were those who smoked $\geq 1$ cigarettes per day. The mothers of neonates included in the study denied the use of alcohol during pregnancy. Cases with complications during pregnancy or labor, such as those who received steroids, had diabetes or preeclampsia, were excluded from the study (Figure 1).

Neonates were appropriate for gestational age and were born by normal vaginal delivery, without use of medications except meperidine. Neonates delivered by cesarean section or epidural anesthesia were excluded. Gestational age was determined according to ultrasonographic criteria and the Ballard's scoring system.
December 2006 to February 2008

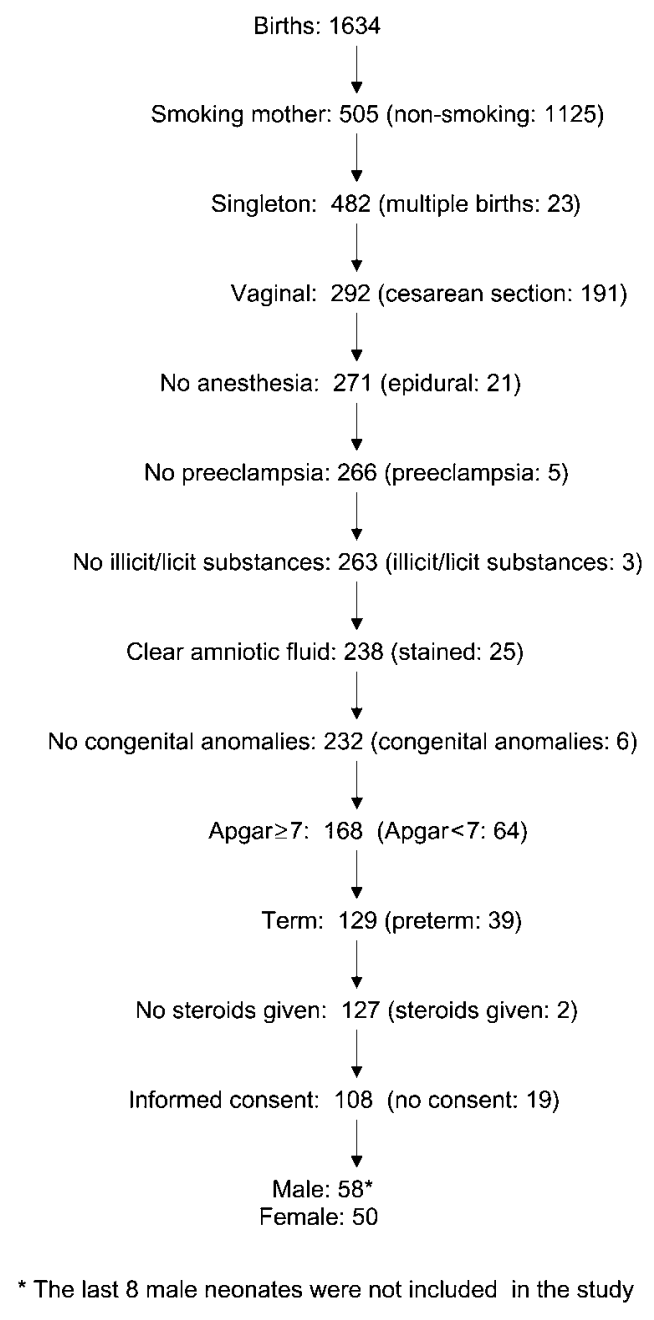

Figure 1 Schematic presentation of the process followed for admission in the study of 100 neonates (50 male, 50 female) born to mothers who smoked during pregnancy.

Birth weight, length and head circumference were measured in all newborns. Also, the placental weight of 165 newborns was recorded. Mixed arteriovenous umbilical blood was collected immediately after delivery, centrifuged and the serum was stored at $-70^{\circ} \mathrm{C}$. Assays were performed in duplicate, and the two measurements were averaged for the analyses.

E3, hPL, $\beta$-hCG, FSH, and LH were assayed by using a standard radioimmunoassay (for E3 and $\beta$-hCG, Radim SpA, Roma, Italy; for hPL, FSH and LH, BioSource Europe SA, Nivelles, Belgium). Cortisol was determined by a fluoroimmunometric assay (Dalfia, Wallac, Inc., Turku, Finland). The sensitivity of the assays for E3, hPL, $\beta$-hCG, FSH, LH, and cortisol was 3.0 $\mathrm{ng} / \mathrm{mL}, 0.25 \mu \mathrm{g} / \mathrm{mL}, 2.0 \mathrm{mlU} / \mathrm{mL}, 0.1 \mathrm{mlU} / \mathrm{mL}, 0.2 \mathrm{mlU} / \mathrm{mL}$, and $0.5 \mu \mathrm{g} / \mathrm{dL}$, respectively.

The study was approved by the Ethics and Deontology Committee of the University Hospital of Patras. Cord blood was obtained with informed consent of the parents.

Data are expressed as mean $\pm S D$ or median with range for parametric and non-parametric continuous variables, respec- 
tively. Hormone values below the sensitivity limit were given zero value and included in the analyses. Student's $t$-test and the Mann-Whitney $U$-test were applied to compare parametric and non-parametric continuous data, respectively. Distributions were evaluated by histograms and the Kolmogorov-Smirnov test. The Spearman rank correlation was used to study the relationship between cord blood hormone concentrations and birth weight, length, head circumference, placental weight and number of cigarettes smoked per day. The relative importance of maternal smoking status or number of cigarettes smoked per day during pregnancy and neonatal gender in predicting cord blood hormone concentrations was calculated in multiple linear logistic regression analyses. For this purpose each cord blood hormone concentration was log transformed and entered as dependent variable. As independent variables were entered the gender and mothers' smoking status expressed as yes/no (Model 1) or as number of cigarettes smoked per day log transformed (Model 2). Variables were analyzed by using the Statistical Package for Social Sciences (SPSS) 15 (SPSS, Inc., Chicago, IL, USA).

\section{Results}

The maternal age, parity and number of cigarettes smoked per day, and the neonatal weight, length, head circumference and placental weight are listed in Table 1.

Table 1 Maternal and neonatal characteristics of 100 cases of mothers who smoked and 100 cases of mothers who did not smoke during pregnancy.

\begin{tabular}{|c|c|c|c|}
\hline Parameter & SM & NSM & P-value \\
\hline \multicolumn{4}{|l|}{ Maternal } \\
\hline Age (years) ${ }^{\star}$ & $28.7 \pm 5.6$ & $28.9 \pm 5.4$ & 0.214 \\
\hline Parity 1 (n) & 42 & 47 & 0.477 \\
\hline Parity 2 (n) & 31 & 36 & 0.464 \\
\hline Parity $\geq 3$ (n) & 27 & 17 & 0.088 \\
\hline No. cigarettes/day** & $5(1-70)$ & - & - \\
\hline \multicolumn{4}{|l|}{ Neonatal } \\
\hline Weight $(g)^{\star}$ & $3095 \pm 333$ & $3209 \pm 297$ & 0.012 \\
\hline Length $(\mathrm{cm})^{\star}$ & $49.8 \pm 1.9$ & $50.4 \pm 1.7$ & 0.024 \\
\hline Head circumference $(\mathrm{cm})^{\star}$ & $34.0 \pm 1.1$ & $34.1 \pm 1.0$ & 0.292 \\
\hline Placental weight $(\mathrm{g})^{\star}$ & $564 \pm 94$ & $605 \pm 92$ & 0.005 \\
\hline
\end{tabular}

*Normally distributed.

${ }^{\star *}$ Not normally distributed.
Anthropometric data were normally distributed, whereas the number of cigarettes smoked per day was not.

Of the six hormones studied, in three (E3, $\beta$-hCG, hPL) the concentrations were significantly lower in the study than in control neonates. Conversely, cortisol concentrations were significantly greater in study neonates (Table 2). Hormone concentrations were not normally distributed.

There was no significant difference in the concentrations of E3, hPL, $\beta$-hCG, FSH, and LH between male and female neonates of either smoking or non-smoking mothers. In the group of neonates whose mothers did not smoke there was a trend of the female neonates to have greater FSH and $\mathrm{LH}$ concentrations, but the difference was not significant (data not shown). However, the cortisol concentrations were significantly greater in female than in male offspring of the non-smoking mothers $(23.3 \mu \mathrm{g} / \mathrm{mL}$ and $11.8 \mu \mathrm{g} / \mathrm{mL}$, respectively; $\mathrm{P}=0.025)$, but the difference did not reach significance in neonates whose mothers smoked $(30.0 \mu \mathrm{g} / \mathrm{mL}$ and $21.7 \mu \mathrm{g} / \mathrm{mL}$, respectively; $\mathrm{P}=0.331$ ).

The simple linear regressions performed to determine a correlation between number of cigarettes smoked per day during pregnancy and birth weight, length, and placental weight showed a significant but poor negative relationship ( $r=-0.188, P=0.008 ; r=-0.156, P=0.027$; $r=-0.257, P=0.01$, respectively). Similarly, significant but poor linear negative relationships were observed between number of cigarettes smoked per day, and E3 $(r=-0.163, P=0.021), h P L(r=-0.191, P=0.007)$, and $\beta$-hCG $(r=-0.143, P=0.044)$ concentrations. Conversely, the cortisol concentrations showed a significant but poor positive correlation to the number of cigarettes smoked per day $(r=0.259, P<0.0001)$.

No significant correlation was found between cord blood hormone concentrations on the one hand and anthropometric measurements of the newborns or the placental weight on the other in both study and control neonates.

Multiple linear regression analyses of E3, hPL, $\beta-\mathrm{hCG}$, $\mathrm{FSH}$, LH and cortisol concentrations were carried out to assess the independent determinants of cord blood hormone concentrations. Data were assessed for model fit

Table 2 E3, $\beta$-hCG, LH, FSH, hPL and cortisol in cord blood of 100 offspring of non-smoking and 100 offspring of smoking mothers.

\begin{tabular}{lccc}
\hline Hormone & Median (range) & & P-value \\
\cline { 2 - 3 } & NSM & SM & 0.008 \\
\hline E3 $(\mathrm{ng} / \mathrm{mL})$ & $212.0(36.8-365.0)$ & $163.0(30.7-365.0)$ & 0.004 \\
$\mathrm{hPL}(\mu \mathrm{g} / \mathrm{mL})$ & $2.00(0.20-7.88)^{\mathrm{a}}$ & $1.39(0.28-7.88)^{\mathrm{b}}$ & 0.037 \\
$\beta-\mathrm{hCG}(\mathrm{mlU} / \mathrm{mL})$ & $57.5(12.2-256.5)$ & $45.4(11.0-115.9)$ & 0.498 \\
FSH $(\mathrm{mlU} / \mathrm{mL})$ & $0.10(0.10-3.4)^{\mathrm{c}}$ & $0.10(0.10-1.82)^{\mathrm{d}}$ & 0.236 \\
LH $(\mathrm{mlU} / \mathrm{mL})$ & $0.20(0.20-4.66)^{\mathrm{e}}$ & $25.1(1.0-129.4)$ & 0.004 \\
Cortisol $(\mu \mathrm{g} / \mathrm{mL})$ & $14.3(1.3-76.3)$ & & \\
\hline
\end{tabular}

$\mathrm{NSM}=$ non-smoking mother; $\mathrm{SM}=$ smoking mother.

The hormone concentration was below the sensitivity limit in: a 26 cases, b28 cases, ${ }^{\circ} 70$ cases, d 73 cases, ${ }^{\circ} 57$ cases, ${ }^{\mathrm{f}} 61$ cases. 
Table 3 Multiple linear regression analyses with log E3, $\beta$-hCG, hPL, FSH, LH, and cortisol as dependent variables.*

\begin{tabular}{|c|c|c|c|c|c|}
\hline \multirow[t]{2}{*}{ Model/hormone } & \multicolumn{2}{|c|}{ Coefficients } & \multicolumn{2}{|l|}{$95 \% \mathrm{Cl}$} & \multirow[t]{2}{*}{$P$-value } \\
\hline & Beta & B & Lower & Upper & \\
\hline \multicolumn{6}{|l|}{ Model 1} \\
\hline E3 & -0.191 & -33.61 & -57.97 & -9.25 & 0.007 \\
\hline $\mathrm{hPL}$ & -0.203 & -0.61 & -1.03 & -0.19 & 0.004 \\
\hline$\beta$-hCG & -0.212 & -18.87 & -31.10 & -6.66 & 0.003 \\
\hline FSH & -0.152 & -0.18 & -0.35 & -0.02 & 0.031 \\
\hline $\mathrm{LH}$ & -0.127 & -0.21 & -0.45 & 0.22 & 0.075 \\
\hline Cortisol & 0.235 & 13.57 & 5.77 & 21.39 & 0.001 \\
\hline \multicolumn{6}{|l|}{ Model 2} \\
\hline E3 & -0.126 & -1.48 & -3.12 & -0.16 & 0.076 \\
\hline $\mathrm{hPL}$ & -0.091 & -0.02 & -0.01 & -0.05 & 0.197 \\
\hline$\beta$-hCG & -0.154 & -0.91 & -7.72 & -0.08 & 0.032 \\
\hline $\mathrm{FSH}$ & -0.073 & -0.01 & -0.22 & -0.06 & 0.343 \\
\hline $\mathrm{LH}$ & -0.056 & -0.01 & -0.22 & -0.09 & 0.432 \\
\hline Cortisol & 0.320 & 1.23 & 0.70 & 1.71 & $<0.0001$ \\
\hline
\end{tabular}

*Only the results to the maternal smoking status as independent variable are listed.

Model 1: As independed variables are included gender and maternal smoking status as dummy variable (yes/no).

Model 2: As Model 1, except that number of cigarettes smoked/day is substituted for smoking status.

and there was no evidence of any departure from the model assumptions. It was found that maternal smoking during pregnancy was a determinant of cord blood E3, hPL, $\beta$-hCG, FSH, and cortisol concentrations in Model 1 (smoking introduced as yes/no), whereas in Model 2 (smoking introduced as number of cigarettes) smoking was a determinant of $\beta$-hCG and cortisol (Table 3). Both smoking status and number of cigarettes per day significantly predicted the decrease and increase in cord blood concentrations of $\beta$-hCG and cortisol, respectively. For $\mathrm{E} 3, \mathrm{hPL}$, and FSH only the smoking status significantly predicted the lower hormone concentrations, whereas the number of cigarettes just failed to reach the level of significance for E3. The LH concentrations were not predicted by maternal smoking status or number of cigarettes smoked per day. Gender was a significant predictor only of higher cortisol concentration in female (median 26.9, range $1.6-129.0 \mu \mathrm{g} / \mathrm{mL}$ ) than in male (median 14.6, range $1.0-129.0 \mu \mathrm{g} / \mathrm{mL}$ ) neonates $(P=0.029)$.

\section{Discussion}

As expected from earlier reports $[17,18]$, the anthropometric parameters studied were lower in neonates of mothers who smoked during pregnancy as well as there were poor but significant negative correlations between number of cigarettes smoked per day and birth weight, length and placental weight. The significantly reduced concentrations of E3, hPL, and $\beta$-hCG in the offspring of mothers who smoked may indicate that tobacco smoking decreases the rate of biosynthesis of these hormones or increases their catabolism by the fetoplacental unit. There are reports showing that cigarette smoking has an antiestrogenic effect [2]. The poor correlations observed between number of cigarettes smoked per day and the concentrations of E3, hPL, $\beta$-hCG, and cortisol do not point to a possible association between the hormone levels in fetuses of smoking women and tobacco smoking. However, the presence of such an association is supported by the results of the multiple linear regression analyses which showed that maternal smoking was a determinant of cord blood concentrations of E3, hPL, $\beta$ hCG, FSH, and cortisol independently of gender. The FSH and LH concentrations in cord blood of neonates whose mothers smoked did not differ significantly from those of neonates of non-smoking women, possibly because in $72 \%$ and $59 \%$ of the cord blood samples, respectively, the hormone concentrations were below the sensitivity limit.

By comparing the results of this study to the effect of smoking on E3 $[3,23,28]$, hPL $[6,23], \beta-h C G ~[3,9,28$, 31 ], and cortisol [34] levels reported in blood of pregnant women, it becomes evident that the effect of tobacco smoking has a different outcome on blood hormone concentrations in the fetus than in the pregnant woman. This indicates that the altered hormone concentrations in cord blood of newborns whose mothers smoked did not result from transfer via the placental barrier; they are rather the consequence of a metabolic rate in the maternal compartment which is different from that in the fetoplacental compartment, and the physiologic events that occur at the boundary between mother and fetoplacental unit.

Cortisol concentrations in cord blood of neonates whose mothers smoked followed the opposite course from that observed in the other five hormones studied. Cortisol is a major stress hormone and it appears that fetal stress induced by tobacco smoking causes dosedepended increased cortisol concentrations. Similarly, 
increased cord blood concentrations of growth hormone, insuline-like growth factor-I and prolactin, hormones that participate in the hormonal stress response as well, have been found in offspring of women who smoked during pregnancy [5]. In this study, mixed arteriovenous cord blood was used because similar concentrations of the hormones studied have been measured in arterial and venous umbilical blood $[12,13,16]$.

As suggested by the absence of a significant correlation between cord blood hormone concentrations and birth size parameters, intrauterine growth was not affected by the hormone levels measured in cord serum in the offspring of both smokers and non-smokers. However, an adverse effect of the disturbed hormonal levels on intrauterine growth cannot be excluded. This is because the hormone concentrations were determined at term and, therefore, it is uncertain whether or not there was an association between fetal growth and any of the hormone concentrations at earlier stages of intrauterine life. It is reported that the production of FSH, LH and $\beta$-hCG is variable during pregnancy $[15,20]$, as well as that the hormone concentrations are greatly increased with the advance of pregnancy, such as it occurs with E3 [33]. A positive association between maternal E3 concentrations at the $27^{\text {th }}$ gestational week and birth weight, birth length and placental weight has been reported [25]. Thus, the findings of this study are limited only to the fetal endocrine profile that exists at the end of pregnancy.

The brain is a target organ for hormonal actions. Specifically, estrogens are potent agents in reference to brain development; they are important during brain development, intervening in the neuronal maturation and the differentiation of brain structures and functions [1, 19]. Estrogens act via two different receptors located in cell nuclei [27]. The brain-endocrine axis during development is delicately balanced and can be disturbed in various ways. Agents that affect normal hormone secretion can influence brain development. Whether or not the decreased cord blood E3 concentrations as well as the altered concentrations of any of the other hormones studied in the offspring of women who smoked during pregnancy can upset normal brain development in the fetus remains unknown at present. However, there are reports indicating that prenatal smoking is associated with psychological problems [7] and brain dysfunction, such as a delay in intellectual development [26], attention deficit hyperactivity disorder [22, 32], conduct disorder $[11,21]$, aggressive disorder [35], and behavior problems [8].

In conclusion, maternal tobacco smoking during pregnancy affects the levels of several hormones in cord blood of term fetuses. The concentrations of E3, hPL, and $\beta-h C G$ are significantly decreased, most probably because of a reduced biosynthesis or, alternatively, because of an increased rate of catabolism. Cortisol concentrations are increased possibly because, as a major stress hormone, it participates in the hormonal stress response induced to the fetus by tobacco smoking. Whether these endocrine abnormalities might lead to any adverse effects on the fetus or adult cannot be assessed at the present.

\section{References}

[1] Arnold AP, Gorski RA. Gonadal steroid induction of structural sex differences in central nervous system. Annu Rev Neurosci. 1984;7:413-42.

[2] Baron JA, LaVecchia C, Levi F. The antiestrogenic effect of cigarette smoking in women. Am J Obstet Gynecol. 1990;162:502-14.

[3] Bartels I, Hoppe-Sievert B, Bockel B, Herold S, Caesar J. Adjustment formulae for maternal serum alpha-fetoprotein, human chorionic gonadotropin, and unconjugated oestriol to maternal weight and smoking. Prenat Diagn. 1993;13: 123-30.

[4] Beratis NG, Panagoulias D, Varvarigou A. Increased blood pressure in neonates and infants whose mothers smoked during pregnancy. J Pediat. 1996;128:806-12.

[5] Beratis NG, Varvarigou A, Makri M, Vagenakis AG. Prolactin, growth hormone and insulin-like growth factor-I in newborn children of smoking mothers. Clin Endocrinol. 1994;40:179-85.

[6] Boyce A, Schwartz D, Hubert C, Cedar L, Dreyfus J. Smoking, human placental lactogen and birth weight. Br J Obstet Gynaecol. 1975:82;964-7.

[7] Button TMM, Maugan B, McGuffin P. The relationship of maternal smoking to psychological problems in the offspring. Early Hum Dev. 2007;83:723-32.

[8] Carter S, Paterson J, Gao W, Lusitini L. Maternal smoking during pregnancy and behavior problems in a birth cohort of 2-year-old Pacific children in New Zealand. Early Hum Dev. 2008;84:59-66.

[9] Crossley JA, Aitken DA, Waugh SML, Kelly T, Connor JM. Maternal smoking: age distribution, levels of alpha-fetoprotein and human chorionic gonadotrophin, and effect on detection of Down syndrome pregnancies in second-trimester screening. Prenat Diagn. 2002;22:247-55.

[10] Divers WA, Wilkes MM, Babaknia A, Yen SSC. Maternal smoking and elevation of catecholamines and metabolites in the amniotic fluid. Am J Obstet Gynecol. 1981;141: 625-8.

[11] Fergusson DM, Woodword LJ, Horwood LJ. Maternal smoking during pregnancy and psychiatric adjustment in late adolescence. Arch Gen Psychiatry. 1998;55:721-7.

[12] Gitau R, Menson E, Pickles V, Fisk NM, Glover V, MacLachlan N. Umbilical cortisol levels as an indicator of fetal stress response to assisted vaginal delivery. Eur J Obstet Gynecol. 2001;98:14-7.

[13] Hagen C, McNeilly AS. The gonadotropic hormones and their subunits in human maternal and fetal circulation at delivery. Am J Obstet Gynecol. 1975;121:926-30.

[14] Handwerger S, Brar A. Placental lactogen, placental growth hormone, and decidual prolactin. Sem Reprod Endocrinol. 1992;10:106-15.

[15] Hay DL. Discordant and variable production of human chorionic gonadotropin and its free alpha- and beta-subunits in early pregnancy. J Clin Endocrinol Metab. 1985; 61:1195-200. 
[16] Hercz P, Várady E, Ungár L, Sicklós P, Büky B. Respiratory distress syndrome: steroid and peptide hormone levels in maternal venous blood and the umbilical vein and artery. Acta Pediatr Hung. 1987;28:17-21.

[17] Kanellopoulos TA, Varvarigou AA, Karatza AA, Beratis NG. Course of growth during the first 6 years in children exposed in utero to tobacco smoke. Eur J Pediatr. 2007; 166:685-92.

[18] Karatza AA, Varvarigou A, Beratis NG. Growth up to 2 years in relationship to maternal smoking during pregnancy. Clin Pediatr. 2003;42:533-41.

[19] MacLasky NJ, Naftolin F. Sexual differentiation of the central nervous system. Science. 1981;211:1294-302.

[20] Massa G, de Zegher F, Vanderschueren-Lodeweyckx M. Serum levels of immunoreactive inhibin, $\mathrm{FSH}$, and $\mathrm{LH}$ in human infants at preterm and term birth. Biol Neonate. 1992;61:150-5.

[21] Maughan B, Taylor A, Caspi A, Moffitt TE. Prenatal smoking and early childhood conduct problems. Arch Gen Psychiatry. 2004;61:836-43.

[22] Milberger S, Biederman J, Faraone SV, Shen L, Jones J. Is maternal smoking during pregnancy a risk factor for attention deficit hyperactivity disorder in children? Am J Psychiatry. 1996;153:1138-42.

[23] Mochizuki M, Maruo T, Masuko K, Ohtsu T. Effects of smoking on fetoplacental-maternal system during pregnancy. Am J Obstet Gynecol. 1984;149:413-20.

[24] Mooney SB, Giudice LC. Endocrinology of pregnancy. In: Rebar RW, editor. Female reproductive endocrinology in Endotext. Available at: http://www.endotext.org/female/. Accessed July 22, 2008.

[25] Mucci LA, Lagiou P, Tamimi RM, Hsien C-C, Adami H-O, Trichopoulos D. Pregnancy estriol, estradiol, progesterone and prolactin in relation to birth weight and other birth size variables (United States). Cancer Causes Control. 2003; 14:311-8.

[26] Naeye RL, Peters EC. Mental development of children whose mothers smoked during pregnancy. Obstet Gynecol. 1984;64:601-7.
[27] Nilsson S, Mäkelä S, Treuter E, Tujague M, Thomsen J, Andersson G, et al. Mechanisms of estrogen actions. Physiol Rev. 2001;81:1535-65.

[28] Palomaki GE, Knight GJ, Haddow JE, Canick JA, Wald NJ, Kennard A. Cigarette smoking and levels of maternal serum alpha-fetoprotein, unconjugated estriol, and hCG: impact on Down syndrome screening. Obstet Gynecol. 1993;81:675-8.

[29] Resnik R, Killam AP, Battaglia FC, Makowski EL, Meschia G. The stimulation of uterine flow by various estrogens. Endocrinology. 1974;94:1192-6.

[30] Salihu HM, Wilson RE. Epidemiology of prenatal smoking and perinatal outcomes. Early Hum Dev. 2007;83:713-20.

[31] Spencer K. The influence of smoking on maternal serum AFP and free beta hCG levels and the impact on screening for Down syndrome. Prenat Diagn. 1998;18:225-34.

[32] Thapar A, Fowler T, Scourfield J, van der Bree M, Thomas $\mathrm{H}$, Harold $\mathrm{G}$, et al. Maternal smoking during pregnancy and attention deficit hyperactivity disorder symptoms in offspring. Am J Psychiatry. 2003;160:1985-9.

[33] Tulchinsky D, Hobel CJ. Plasma human chorionic gonadotropin, estrone, estradiol, estriol, progesterone, and 17 alpha-hydroxyprogesterone in human pregnancy. Am J Obstet Gynecol. 1973;117:884-93.

[34] Varvarigou AA, Petsali $M$, Vassilakos $P$, Beratis NG. Increased cortisol concentrations in the cord blood of newborns whose mothers smoked during pregnancy. $\mathrm{J}$ Perinat Med. 2006;34:466-70.

[35] Williams GM, O'Callaghan M, Najman JM, Bor W, Andersen MJ, Richards D, et al. Maternal cigarette smoking and child psychiatric morbidity: a longitudinal study. Pediatrics. 1998;102:e11.

The authors stated that there are no conflicts of interest regarding the publication of this article.

Received June 14, 2008. Revised November 18, 2008. Accepted November 24, 2008. Previously published online March 17, 2009. 